\section{Preparation of Catalytically Active Palladium Nanoclusters in Compartments of Amphiphilic Hyperbranched Polyglycerols}

\section{Stefan Mecking,* Ralf Thomann, Holger Frey, and Alexander Sunder}

Institut für Makromol ekulare Chemie und Freiburger Material forschungszentrum der Al bert-Ludwigs-U niversität Freiburg, Stefan-Meier-Str. 31, D-79104 Freiburg, Germany

Transition metal clusters and colloids of narrow particle size distributions in the range $1-10 \mathrm{~nm}$ are currently subject to intense research efforts. ${ }^{1} \mathrm{From}$ a fundamental perspective, the transition from the properties of the bulk to those of molecular clusters is expected to occur in this size range. A transition metal cluster of $2 \mathrm{~nm}$ diameter consists of a few hundred atoms, a large portion of which are located at the surface of the cluster. In view of potential applications, such materials are of interest with regard to for example catalysis ${ }^{2,3 a, f, 4 c, 5 b, 6 \mathrm{~d}}$ or mi croel ectronics. ${ }^{1 \mathrm{a}, \mathrm{b}}$ H owever, increasing the control of particle size and the stability of the metal colloid solutions remain key challenges. Recent approaches to the controlled preparation of metal or semiconductor nanoparticles have utilized surfactants $^{21,3}$ or the self-assembled nanostructures of block copolymer micelles, ${ }^{2 t, 4}$ achieving an unprecedented control of particle size and also spatial organization in thin films by the latter method. However, such template structures self-assembled from a larger number of individual molecules are by their very nature dynamic in solution. Thus, their size and aggregation numbers are subject to fluctuations, and such structures can be shear-sensitive. To stabilize micelle-like structures, polymerized micelles ${ }^{5}$ and very recently dendrimers ${ }^{6}$ have been employed as mol ecular compartments for the preparation of metal particles. Whereas dendrimers ${ }^{7}$ offer the advantage of a well-defined structure, their syntheses are usually tedious. By contrast to the perfectly branched structure of dendrimers, hyperbranched polymers $\mathrm{s}^{8}$ possess a randomly branched structure. They can be prepared conveniently in one-pot procedures; however, usually polymers of extremely broad molecular weight distributions are obtained. In a recent approach, amphiphilic hyperbranched poly(glycerols) of low polydispersity $\left(\mathrm{M}_{\mathrm{w}} / \mathrm{M}_{\mathrm{n}}<1.7\right)$ were prepared by anionic multibranching polymerization of glycidol, ${ }^{9}$ followed by partial esterification of the $\mathrm{OH}$ functions with long chain fatty acids (Scheme 1). ${ }^{10}$ Such amphiphilic macromolecules function as nanocapsules, incorporating individual hydrophilic dye molecules as guests. ${ }^{10}$ We now report on the application of these easily accessible, well-defined amphiphilic mol ecules for the preparation of nanometer-size stable palladium colloids and their application in catalysis.

In the following experiments, amphiphilic polymers prepared by esterification of $60-67 \%$ of the $\mathrm{OH}$ functions of poly(glycerol) scaffolds of different molecular weights with palmitoyl chloride were empl oyed. ${ }^{11}$ Solutions of these polymers in apolar organic solvents, such

* Author to whom correspondence should be addressed. E-mail mecking@ruf.uni-freiburg.de; Fax +49 761 203-6319. as toluene or chlor oform, solubilize $\mathrm{PdCl}_{2}$ to yield yel low solutions of the otherwise insoluble metal salt. Exposure of such tol uene solutions to hydrogen ( $1 \mathrm{~atm}$ ) or heating to $60^{\circ} \mathrm{C}$ for several hours resulted in a slow reduction, ${ }^{12}$ ultimately yielding clear dark, brownish metal colloid solutions. ${ }^{20}$ E mploying $\mathrm{Pd}(\mathrm{OAC})_{2}$ as a precursor, similar results were obtained. In all cases, no deposition of metallic palladium was observed. By comparison, in the absence of the amphi philic polyglycerol, reduction was accompanied by immediate precipitation of palladium black. A molar ratio Pd(II) salt/polymer corresponding to as low as ca. $2 \mathrm{OH}$ groups of the polymer/Pd was employed. The nanometer-sized palladium particles formed were visualized by transmission electron microscopy ${ }^{13}$ (TEM). Employing an amphiphilic polymer prepared from a poly(glycerol) scaffold of $D P_{n}=63$ at a high metal loading ( $4 \mathrm{OH} / \mathrm{Pd})$, a colloid of $5.2 \pm 1.8 \mathrm{~nm}$ average particle size was obtained (Figure 1a). Utilization of a smaller amphiphilic polyglycerol $\left(D P_{n}=23\right)$ under otherwise identical conditions resulted in a decrease in metal cluster size to $2.1 \pm 0.6 \mathrm{~nm}$ (Figure 1b). In view of these observed cluster particle sizes, some of the clusters may be stabilized by more than one amphiphilic polymer molecule in both cases. ${ }^{14,15} \mathrm{How}$ ever, upon reducing the high metal-to-polymer ratios 10-fold, much smaller metal particles were obtained, meeting the limit of resolution (ca. $1 \mathrm{~nm}$ ) of TEM analysis. Such particle sizes are clearly in the range expected for stabilization of a cluster in a unimolecular micelle-type structure. The colloidal solutions were found to be stable in air for at least several months at room temperature. Complete evaporation of solvent and drying in vacuo resulted in formation of dark oils, which could be redissolved (e.g., in olefinic substrates; vide infra) to yield clear dark solutions again.

Dendrimers ${ }^{6}$ or block copolymers ${ }^{4}$ used in previous related studies usually contain nitrogen donor atoms to enable initial coordination of metal salt precursors prior to reduction as well as subsequent stabilization of metal clusters formed by reduction of the metal salt. The presence of such coordinating moieties can be disadvantageous, e.g., by blocking of active sites in catalysis. By contrast, the polyglycerol-based system reported contains highly polar, but weakly coordinating, $\mathrm{OH}$ functions. As a first probe for the applicability of these polymer-stabilized colloids in catalysis, the hydrogenation of cyclohexene was investigated. Well-behaved kinetics were observed, a high rate $\mathrm{e}^{16}$ of ol efin consumption being sustained throughout the course of the reaction. For example, $75 \%$ conversion $\equiv 22.000$ TO corresponded to an overall average rate of $700 \mathrm{TO} \mathrm{h}^{-1}$ $\operatorname{atm}\left(\mathrm{H}_{2}\right)^{-1}$ (cf. Supporting I nformation). These turnover numbers (i.e., combination of high rate and catalyst stability) compare favorably to previous reports on hydrogenation of cyclohexene by solutions of palladium colloids. ${ }^{21,4 c, 17}$ A commercially available Pd/activated charcoal catalyst was found to display a somewhat lower activity under identical conditions. These results clearly demonstrate good accessibility of the colloidal metal for the substrate in our system. Recycling the catalyst, no significant decrease in activity was observed. Also, no deposition of palladium was observed in repeated runs, evidencing the stability of the metal colloids during catalysis. As for the stability of the amphiphilic polymer 
Scheme 1. Schematic Representation of Polymer Synthesis and Structure ${ }^{9,10}$

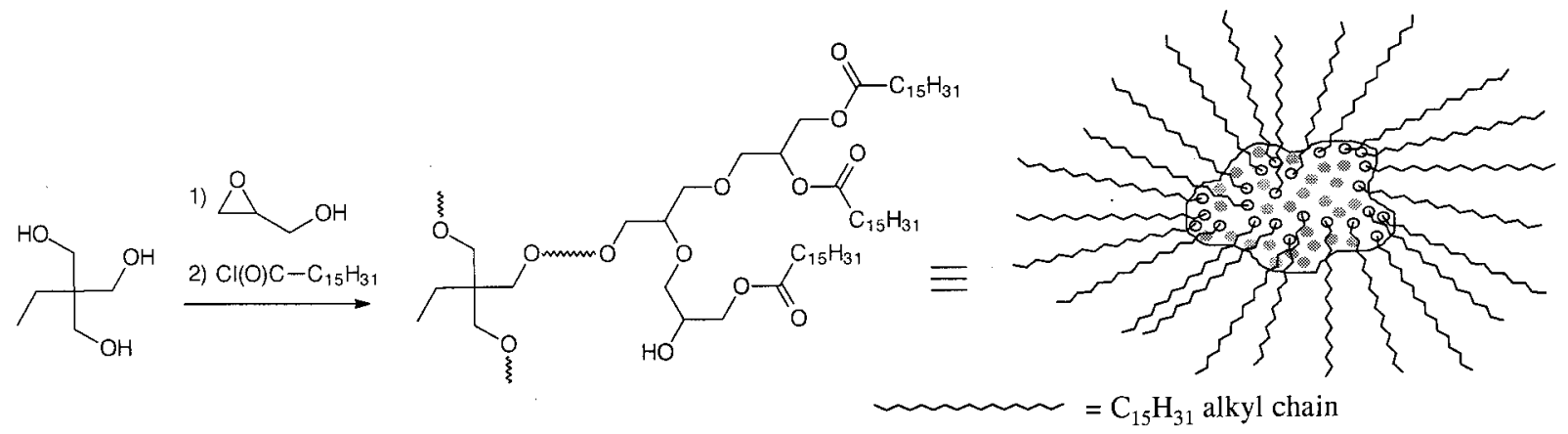

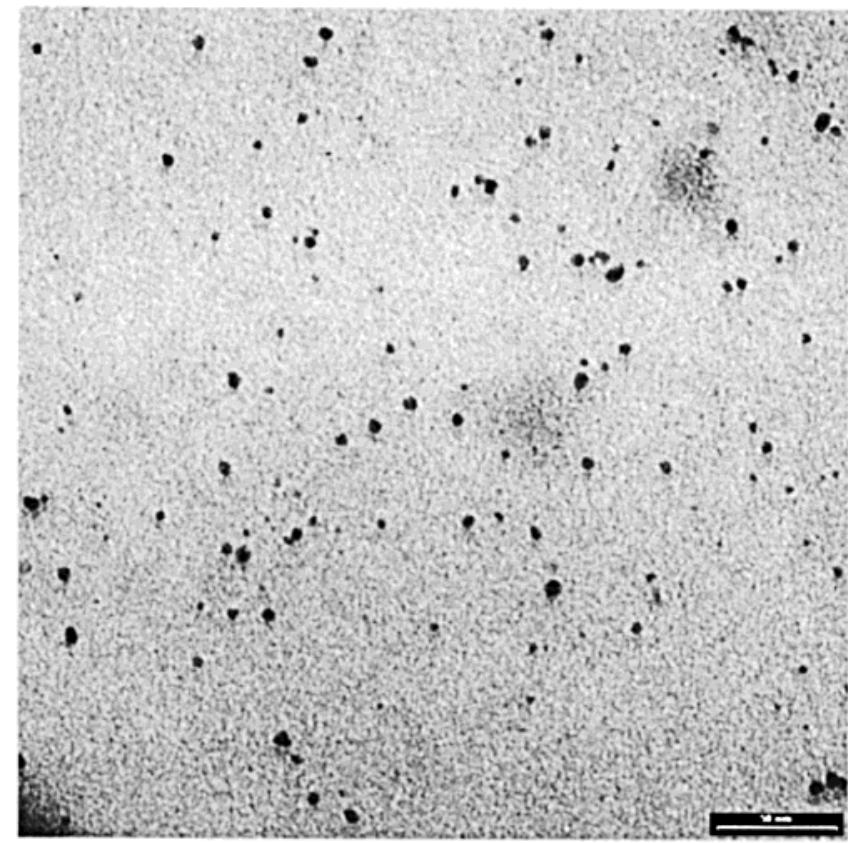
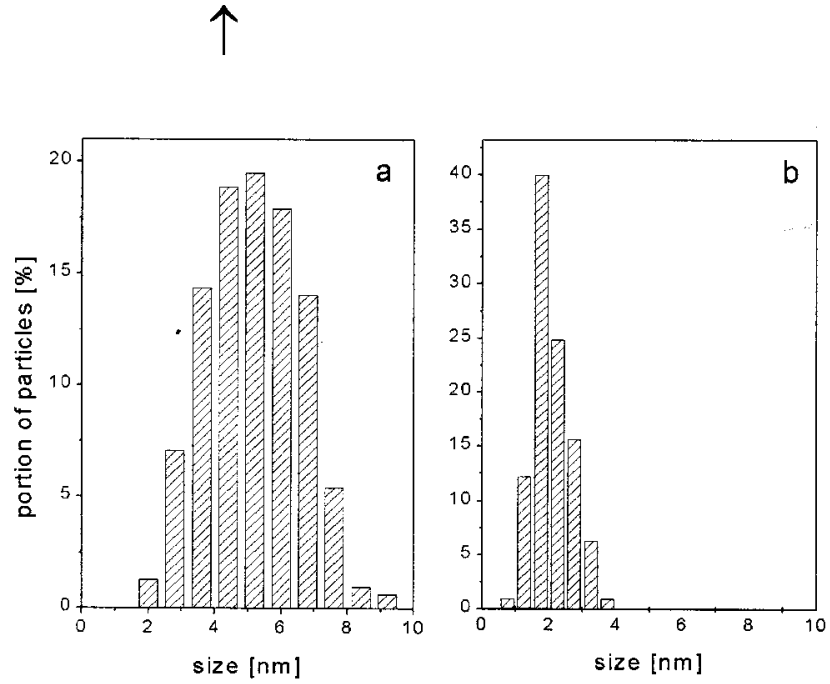

Figure 1. TEM image and histograms of palladium colloids prepared with polymer of (a) scaffold $\mathrm{DP}_{\mathrm{n}}=63$ and (b) scaffold $\mathrm{DP}_{\mathrm{n}}=23$. Scale bar $=50 \mathrm{~nm}$.

matrix under reactions conditions, ester groups are generally considered to be quite stable under the conditions of $\mathrm{Pd}^{0}$-catalyzed hydrogenation reactions. ${ }^{18}$ Indeed, proton NMR and GPC analysis after repeated runs revealed no change of the polymer structure. Apart from simple distillation (in vacuo), separation of the products from the metal colloid could also be achieved by dialysis (benzoylated cellulose, Aldrich, molecular weight cutoff 1000 ) or by ultrafiltration on a suitable solvent-stable membrane (Koch Membrane Systems, MPF type) without any apparent deposition of metal on the membranes, which is of interest for example in view of catalytic conversions in continuously operated membrane reactors. ${ }^{19}$

In conclusion, stable solutions of metal colloids in organic solvents can be prepared conveniently by employing a readily accessible well-defined amphiphilic hyperbranched polymer. The metal cluster size is dependent upon the molecular weight of the polymer. High activity and stability of the colloids in catalysis have been demonstrated. To the best of our knowl edge, these findings represent the first application of a hyperbranched amphiphilic structure to the preparation of nanometer-sized metal colloids as well as the first application of synthetic hyperbranched polymers to transition metal catalysis.

Acknowledgment. We thank R. Mülhaupt for his generous support. Financial support by the Deutsche Forschungsgemeinschaft (SFB 428) is gratefully acknowledged. A generous loan of palladium chl oride was provided by Degussa-Hüls AG. S.M. thanks G. Moerber for his excellent technical assistance.

Supporting Information Available: Graphical representation (productivity and conversion vs reaction time) of cyclohexene hydrogenation.

\section{References and Notes}

(1) (a) Bradley, J . S. In Clusters and Colloids: From Theory to Applications; Schmid, G., Ed.; VCH: Weinheim, 1994; pp 459-544. (b) Nanoparticles and Nanostructured Films; Fendler, J . H., Ed.; Wiley-VCH: Weinheim, 1998. (c) Active Metals: Preparation, Characterization, Applications; Fürstner, A., Ed.; VCH: Weinheim, 1996.

(2) Leading references: (a) Turkevich, J .; Kim, G. Science 1970, 169, 873-9. (b) Kraeutler, B.; Bard, A. J . J . Am. Chem. Soc. 1978, 100, 4317-8. (c) Klabunde, K. J .; I mizu, Y. J . Am. Chem. Soc. 1984, 106, 2721-2. (d) Hirai, H. Makromol Chem. Supp. 1985, 14, 55-69. (e) Boutonnet, M.; Kizling, J .; Tourode, R.; Maire, G.; Stenius, P. Appl. Catal. 1986, 20, 163-77. (f) Bradley, J . S.; Hill, E.; Leonowicz, M. E.; Witzke, H. J . Mol. Catal. 1987, 41, 59-74. (g) Vargaftik, M. N.; Zagorodnikov, V. P.; Stolarov, I. P.; Moiseev, I. I.; Kochubey, D. I.; Likholobov, V. A.; Chuvilin, A. L.; Zamarev, K. I. J . Mol. Catal. 1989, 53, 315-48. (h) Schmid, G. Chem. Rev. 1992, 92, 1709-27. (j) Lewis, L. N. Chem. Rev. 1993, 93, 2693-2730. (k) Behr, A.; Schmidke, H. Chem.-Ing.Techn. 1993, 65, 568-9. (I) Boennemann, H.; Brijoux, W.; Brinkmann, R.; Fretzen, R.; J oussen, T.; Koeppler, R.; Korall, B.; Neiteler, P.; Richter, J . J . Mol. Catal. 1994, 86, 129-77. (m) van Benthem, R. A. T. M.; Hiemstra, H.; van Leeuwen, P. W. N. M.; Geus, J . W.; Speckamp, W. N. Angew. Chem., Int. Ed. Engl. 1995, 34, 547-50; Angew. Chem. 1995, 
107, 500-3. (n) Duff, D. G.; Mallat, T.; Schneider, M.; Baiker, A. Appl. Catal. A 1995, 133, 133-48. (o) Henglein, A.; Ershov, B. G.; Malow, M. J. Phys. Chem. 1995, 99, 14129-36. (p) Bönnemann, H.; Braun, G. A. Angew. Chem., Int. Ed. Engl. 1996, 35, 1992-5. (q) Beller, M.; Fischer, H.; Kuehlein, K.; Reisinger, C.-P.; Herrmann, W. A. J . Organomet. Chem. 1996, 520, 257-259. (r) Reetz, M. T.; Lohmer G. J. Chem. Soc., Chem. Commun. 1996, 1921-2. (s) Schmid, G.; West, H.; Malm, J .-O.; Bovin, G. C.; Grenthe, C. Chem. Eur. J . 1996, 9, 1099-103. (t) Klingelhoefer, S. Heitz, W.; Greiner, A.; Oestreich, S.; F oerster, S.; Antonietti, M. J. Am. Chem. Soc. 1997, 119, 10116-20. (u) Aiken, J. D. Finke, R. G. J Am. Chem. Soc 1999, 121, 8803-10.

(3) (a) Kiwi, J .; Grätzel, M. J . Am. Chem. Soc. 1979, 101, 72147. (b) Boutonnet, M.; Kizling, J .; Stenius, P.; Maine, G. Colloids Surf. 1982, 5, 209-25. (c) Toshima, N.; Takahashi, T.; Hirai, H. Chem. Lett. 1985, 1245-8. (d) Wiesner, J.; Wokaun, A.; Hoffmann, H. Prog. Colloid Polym. Sci. 1988, 76, 271-7. (e) Satoh, N.; Kimura, K. Bull. Chem. Soc. J pn. 1989, 62, 1758-63. (f) Boennemann, H.; Brijoux, W.; Brinkmann, R.; Dinjus, E.; J oussen, T.; K orall, B. Angew. Chem., Int. Ed. Engl. 1991, 30, 1312-4; Angew. Chem. 1991, 103, 1344-6. (g) Larpent, C.; Brisse-Le Menn, F.; Patin, H. J. Mol. Catal. 1993, 65, L35-40. (h) Reetz, M. T.; Hel big, W. J. Am. Chem. Soc. 1994, 116, 7401-2. (i) Reetz, M. T.; Maase, M. Adv. Mater. 1999, 11, 773-6.

(4) (a) Ng Cheong Chan, Y. Craig, G. S. W.: Schrock, R. R Cohen, R. E. Chem. Mater. 1992, 4, 885-94. (b) Saito, R. Okamura, S.; Ishizu, K. Polymer 1992, 33, 1099-1101. (c) Antonietti, M.; Wenz, E.; Bronstein, L.; Seregina, M. Adv. Mater. 1995, 7, 1000-5. (d) Spatz, J. P.; Roescher, A.; Moeller, M. Adv. Mater. 1996, 8, 337-340. (e) Moffitt, M.; Eisenberg, A. Chem. Mater. 1995, 7, 1178-84. (f) Moeller, M.; Spatz, J . P. Curr. Opin. Colloid I nterface Sci. 1997, 2, 177-187. (g) Bronstein, L.; Antonietti, M.; Valetsky, P. In ref $1 b$, pp 145-71.

(5) (a) Kurihara, K.; Fendler, J . H. J . Am. Chem. Soc. 1983, 105, 6152-3. (b) Kurihara, K.; Fendler, J. H.; Ravet, I.; Nagy, J. B. J . Mol. Catal. 1986, 34, 325-335. (c) Toshima, N.; Takahashi, T.; Hirai, H. Chem. Lett. 1986, 35-38. (d) Toshima, N.; Takahashi, T.; Hirai, H. Chem. Lett. 1987, 1031-4.

(6) (a) Zhao, M.; Sun, L.; Crooks, R. M. J . Am. Chem. Soc. 1998 120, 4877-8. (b) Balogh, L.; Tomalia, D. A. J. Am. Chem. Soc. 1998, 120, 7355-6. (c) Esumi, K.; Suzuki, A.; Aihara, N.; Usui, K.; Torigoe, K. Langmuir 1998, 14, 3157-9. (d) Zhao, M.; Crooks, R. M. Angew. Chem., Int. Ed. Engl. 1999, 38, 364-6; Angew. Chem., 1999, 111, 375-7.

(7) Recent reviews: (a) Fischer, M.; Vögtle, F. Angew. Chem., Int. Ed. Engl. 1999, 38, 884-905; Angew. Chem. 1999, 111, 934-955. (b) Bosman, A. W.; J anssen, H. M.; Meijer, E. W. Chem. Rev. 1999, 99, 1665-88.
(8) Hyperbranched polymers: (a) Frechet, J . M. J .; Henmi, M. Gitsov, I.; Aoshima, S.; Leduc, M. R.; Grubbs, R. B. Science 1995, 269, 1080-3. (b) Voit, B. I. Acta Polym. 1995, 46, 8799. (c) Kim, Y. H. J . Polym. Sci., Polym. Chem. Ed. 1998 36, 1685-98. (d) Flory, P. J . J . Am. Chem. Soc. 1952, 74, $2718-2723$.

(9) Sunder, A.; Hanselmann, R.; Frey, H.; Mülhaupt, R. Macromolecules 1999, 32, 4240-4246.

(10) Sunder, A.; Krämer, M.; Hanselmann, R.; Mülhaupt, R.; Frey, H. Angew. Chem., Int. Ed. Engl. 1999, 38, 3552-5; Angew. Chem. 1999, 111, 3758-61.

(11) Poly(glycerol) scaffolds were prepared using trimethylolpropane as an initiator, ${ }^{9}$ amphiphilic modification by partial esterification as previously described. ${ }^{10}$ All samples employed displayed a low polydispersity of $\mathrm{M}_{w} / \mathrm{M}_{n}<1.5$.

(12) In the reduction upon heating, the $-\mathrm{OH}$ moieties of the polymer may function as a reducing agent. Cf. Hirai, $\mathrm{H}$.; Nakao, Y.; Toshima, N. J . Macromol. Sci., Chem. 1979, A13, 727-50.

(13) TEM images were obtained on a LEO 912 Omega microscope at an accelerating voltage of $120 \mathrm{kV}$.

(14) Roughly estimating the size of a single amphiphilic molecule for comparison, for the $\mathrm{DP}_{\mathrm{n}}=63$ polymer a diameter of 4 $\mathrm{nm}$ is calculated for a spherical, nonswollen molecule.

(15) Due to a certain flexibility of the branched polyether backbone, an organization of several molecules around a cluster is possible.

(16) $\mathrm{TO}=$ turnovers, i.e., moles of cyclohexane formed per mole of palladium (calculated with respect to the entire amount of Pd present in the clusters, i.e., activity of the significant surface atoms will be higher)

(17) (a) Seregina, M. V.; Bronstein, L. M.; Platonova, O. A.; Chernyshov, D. M.; Valetsky, P. M.; Hartmann, J .; Wenz, E.; Antonietti, M. Chem. Mater. 1997, 9, 923-31. (b) Mayer, A. B. R.; Mark, J . E. J . Polym. Sci., Polym. Chem. 1997, 35, 3151-60.

(18) Cf. (a) Encyclopedia of Reagents for Organic Synthesis; Paquette, L. A., Ed.; J ohn Wiley: New York, 1995; Vol. 6 pp 3867-72. (b) Sato, M.; Sakaki, J .; Sugita, Y.; Nakano, T.; Kaneko, C. Tetrahedron Lett. 1990, 31, 7463-7466.

(19) (a) Hovestad, N. J .; Eggeling, E. B.; Heidbuechel, H. J .; J astrzebski, J . T. B. H.; Kragl, U.; Keim, W.; Vogt, D.; van Koten, G. Angew. Chem., Int. Ed. Engl. 1999, 38, 1655-58; Angew. Chem. 1999, 111, 1763-5. (b) Brinkmann, N.; Giebel, D.; Lohmer, G.; Reetz, M. T.; Kragl, U. J . Catal. 1999, 183, 163-8.

(20) Reduction with carbon monoxide occurred much faster, affording clear dark colloid solutions within minutes. 